Journal of Computer Science 5 (11): 788-793, 2009

ISSN 1549-3636

(C) 2009 Science Publications

\title{
A Performance Study of Reactive Multicast Routing Protocols in Virtual Class Room Using Mobile Ad Hoc Network
}

\author{
${ }^{1}$ S. Vijayaragavan, ${ }^{1}$ K. Duraiswamy, ${ }^{2}$ B. Kalaavathi and ${ }^{1}$ S. Madhavi \\ ${ }^{1}$ Department of Computer Science and Engineering, KS Rangasamy College of Technology, \\ Kalvi Nagar, Tiruchengode-637215, India \\ ${ }^{2}$ Department of Information Technology, KS Rangasamy College of Technology, \\ Kalvi Nagar, Tiruchengode-637215, India
}

\begin{abstract}
Problem statement: A great deal of excitement has recently propelled Mobile Learning to the forefront of educational technology. The exponential growth of mobile technology in the recent years, increase in the availability of high-bandwidth network, advances in wireless technologies and popularity of handheld devices, have opened up new accessibility opportunities for education. Approach: Virtual class room using MANET had been proposed to enhance the m-Learning opportunities in a residential institution. Results: This environment transferred both large and small volume of data to the particular group members. Generally multicasting supports group oriented computing. Such a group oriented service required a suitable multicast routing protocol. Two standard multicast routing protocols were implemented and analyzed for tree (MAODV) and mesh (ODMRP) based approach. The performances of group learning module of VCR had been analyzed using MAODV and ODMRP routing protocols for parameters such as network traffic, the node speed and the network area. Conclusion/Recommendations: Our results showed that many scenarios in VCR environment, MAODV achieved a higher packet delivery ratio than ODMRP.
\end{abstract}

Key words: Mobile learning, mobile ad hoc network, personal digital assistant, multicast routing, virtual class room

\section{INTRODUCTION}

Mobile learning activities can be suited to an indoor or outdoor environment. Also, either a single learner or a group of learners can participate in the learning activity. The ad hoc classroom can support urgent and timely learning activities, thus improving learning effectiveness.

The Ad Hoc and mobile virtual classroom system offers students with wireless access to electronic books, knowledge and teaching material and offer learners mobility and multiple interactive opportunities. Through the use of the Virtual Class Room system, students can download or upload their homework, teacher's announcements, or do exercises, anytime and anywhere.

MANETs are infrastructureless wireless networks where nodes are capable of moving. They are formed dynamically by a collection of arbitrarily located wireless mobile nodes without much set up time or cost and without the use of existing network infrastructure or centralized administration. Generally, some or all nodes of a MANET function as routers and communication between two hosts is done by multi-hop routing through the nodes of the network. Devices such as laptops, PDAs, mobile phones, pocket PC with wireless connectivity are commonly used.

Multicasting is intended for group-oriented computing. There are more and more applications where one-to-many dissemination is necessary. The multicast service is critical in applications characterized by the close collaboration of teams (e.g., rescue patrol, battalion, scientists, VCR) with requirements for audio and video conferencing and sharing of text and images. The use of multicasting within a network has many benefits. Multicasting reduces the communication costs for applications that send the same data to multiple recipients. Instead of sending via multiple unicast, multicasting minimizes the link bandwidth consumption, sender and router processing and delivery delay. Maintaining group membership information and building optimal multicast trees is challenging even in wired networks. Routing is needed to find a path between source and destination and to forward the packets appropriately.

Corresponding Author: S. Vijayaragavan, Department of Computer Science and Engineering,

KS Rangasamy College of Technology, KSR Kalvi Nagar, Tiruchengode-637215, India 
When it became clear that group-oriented communication is one of the key application classes in MANET environments, a number of MANET multicast routing protocols have been proposed ${ }^{[1-3,5-7]}$. These protocols can be classified according to two different criteria. The first criterion has to do with maintaining routing state and classifies routing mechanisms into two types: proactive and reactive. Proactive protocols maintain routing state, while the reactive reduce the impact of frequent topology changes by acquiring routes on demand.

The second criterion classifies protocols according to the global data structure used to forward multicast packets. Existing protocols are either tree- or meshbased. As in fixed (non-mobile) multicast routing, treebased protocols build a tree over which multicast data is forwarded. The tree-based protocols do not always offer sufficient robustness even though they are bandwidth efficient. Certain key features of MANETs, such as fast deployment, make them well-suited for critical environments (e.g., battlefield or disaster recovery) where robustness and reliability are essential. Thus, one of the main challenges for multicast routing in MANETs is the need to achieve robustness in the presence of universal mobility and frequent node outages. For this purpose, mesh-based protocols build a mesh for forwarding multicast data and thus address robustness and reliability requirements with path redundancy inherent to meshes.

The focus of our work is to suite the multicast routing protocol for VCR application. Our implementation compares the performance of the OnDemand Multicast Routing Protocol (ODMRP) ${ }^{[2]}$ as the representative of mesh-based protocols against Multicast Ad hoc On-demand Distance Vector (MAODV) ${ }^{[5]}$ representing tree-based schemes. Both protocols belong to the reactive category. The performances of group learning module of VCR are analyzed using MAODV and ODMRP routing protocols for parameters are network traffic, the node speed and the area.

The organization of the paper is as follows: The details of software components and hardware components needed for establishment of VCR are illustrated. MAODV and ODMRP routing protocols are explained. The system design is described. The performance comparisons of the above two routing protocols are presented. Finally, conclusion of this study is presented.

\section{MATERIALS AND METHODS}

Establishment of virtual class room: VCR is a class room, where group members can be interconnected with each other by MANET spread for a area of $500 \mathrm{~m}$ as shown in Fig. 1. VCR can be immediately established and members can be dynamically added or removed within the range at any time. VCR can support timely learning activities, thus improving learning effectiveness. For example, a teacher may establish a VCR from his or her residence; students located within the area of 500 $\mathrm{m}$ exploit the opportunity to form the ad hoc group to improve the teaching-learning process at any time using standard IEEE 802.11 with Peer-to-Peer (P2P) capability enabled PDA.

The VCR involves three essential elements. The first element is a teacher and a group of students. The teacher can be a traditional instructor or a group leader. The second essential element is the mobile instructional device used by the teacher and the students. The third element is the communication infrastructure. The dynamic communication infrastructure consists of $\mathrm{P} 2 \mathrm{P}$ communication among the learning devices of the students and the instructional device of the teacher. VCR has been designed to enhance group learning.

Any student member can request for study material or initiate discussion either with the instructor or with any other student member in the group by using group learning module. VCR has been designed to support both text based discussion and transfer of study materials in a form of compound file which contains multimedia data.

Components of virtual class room: The main component of VCR is P2P capability enabled Personal Digital Assistant (PDA). For the convenient use of PDA, each PDA is named and its IP address is assigned manually. The host address part of students IP address is assigned based on their PDA ID. For example, Tutor as PDA ID and IP address as 192.168.25.30, CSE01 as a first student PDA ID and IP address as 192.168.25.31, CSE02 as a first student PDA ID and IP address as 192.168.25.32.

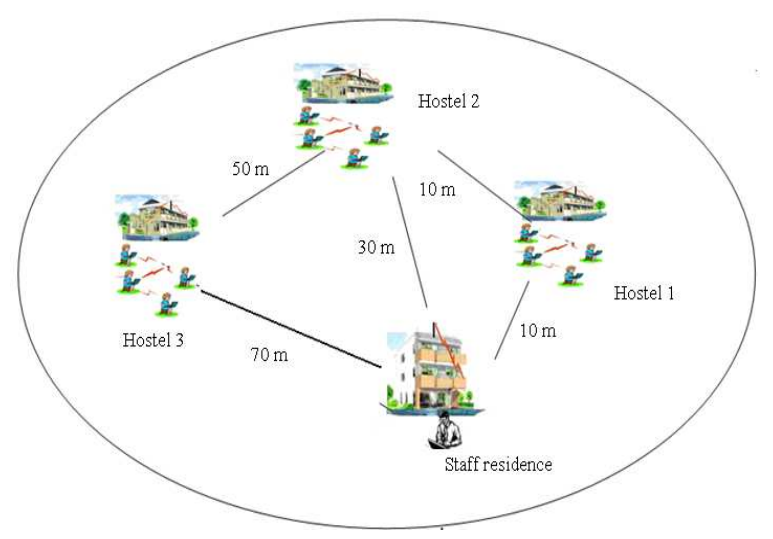

Fig. 1: A scenario of VCR using MANET 
VCR-hardware components are as follows:

- 1 Compaq Intel® Pentium® M CPU $1.60 \mathrm{GHz}$, 504 MB of RAM: Main development environment

- 30 i-mate PDAL: Targeted platform

- 30 san disk micro SD memory card 1 GB: Storage memory

VCR-software components are as follows:

- Microsoft visual studio .NET, C\# 2005: Main programming tool

- Microsoft windows mobile 5.0 pocket PC SDK: Pocket PC platform builder

- Microsoft ActiveSync version 4.2: Synchronization software for pocket PC

- Microsoft .Net compact framework 2.0: Pocket PC .NET platform runtime

Multicast protocols for MANET: Multicast Ad hoc On-demand Distance Vector protocol (MAODV): MAODV $^{[5]}$ is a multicast extension of AODV. In MAODV, all members of a multicast group are formed into a tree (which includes non-member nodes required for the connection of the tree) and the root of the tree is the group leader. Multicast data packets are propagated among the tree. The core of the MAODV protocol is about how to form the tree, repair the tree when a link is broken and how to merge two previously disconnected trees into a new tree.

There are four types of packets in MAODV: Route Request (RREQ), Route Reply (RREP), Multicast Activation (MACT) and Group Hello (GRPH). RREQ and RREP are also packets in AODV. A node broadcasts a RREQ, when it is a member node and wants to join the tree, or it is a non-member node and has a data packet targeted to the group.

When a node in the tree received RREQ, it responses with RREP using unicast. Since RREQ is broadcasted, there may be multiple RREP's received by the originating node. The originating node should select one RREP that has the shortest distance to the tree and unicast a MCAT along the path to set up a new branch to the tree.

GRPH is the group hello packet, it is periodically broadcasted by group leader to let the nodes in the tree to update its distance to the group leader.

On-Demand Multicast Routing Protocol (ODMRP): $\mathrm{ODMRP}^{[2]}$ is a mesh based rather than a conventional tree based scheme and uses a forwarding group concept (only a subset of nodes forwards the multicast packets via scoped flooding).

In ODMRP, group membership and multicast routes are established by the source on demand when a multicast source has packets to send, but no route to the multicast group, it broadcasts Join-Query control packets to the entire network. This control packet is periodically broadcast to refresh the membership information and updates routes. When the Join-Query packet reaches a multicast receiver, it creates and broadcasts Join-Reply to its neighbors. When it has been received by the node, it checks if the next hop node id of one of the entries in Join-Reply table matches its own id. If it is does, the node realizes that it is on the path to the source and becomes the part of the forwarding group by setting the FG_FLAG (Forwarding Group flag). When receiving a multicast data packet, a node forwards it only when it is not a duplicate, hence minimizing traffic overhead. Because the nodes maintain soft state, finding the optimal flooding interval is critical to ODMRP performance.

ODMRP uses location and movement information to predict the duration of time that routes will remain valid. With the predicted time of route disconnection, a "join data" packet is flooded when route breaks of ongoing data sessions are imminent.

System design: The C\# in Microsoft.NET Compact Framework 2005 has been used to develop this VCR using MANET. In C\#, User Datagram Protocol (UDP) is used to create unicast, multicast and broadcast sockets for sending and receiving packets (control packet or data packet). Listener thread is created to listen to arrival of packets. By using delegate (pointer to function), the client functionalities like packet sending and handling have been performed. UDP is chosen to send and receive packets and its size is set to 512 bytes.

Packet types: The group learning module in VCR starts transmission by discovering a route. The general packet types used in the routing protocols are route request, route reply, multicast activation, data packet, route repair, route error and group hello.

Packet contents: The packet format used for communication between a source node and a destination node contains some of the following fields:

Type, source address, group ID, group IP, hop count, reverse hop count, path, destination address, current ID, receipt ID, TTL, sequence number, payload, lifetime, flags, group sequence number.

\section{RESULTS AND DISCUSSION}

Qualitative comparative study of MAODV and ODMRP: The Table 1 shown below has given the side by side comparison of the two protocols. 
Table 1: Qualitative features of MAODV and ODMRP

\begin{tabular}{|c|c|c|}
\hline Characteristics & MAODV & ODMRP \\
\hline Unicast supportability & $\begin{array}{l}\text { Yes uses AODV } \\
\text { unicast table }\end{array}$ & No \\
\hline $\begin{array}{l}\text { Multicast support } \\
\text { required on each node }\end{array}$ & $\begin{array}{l}\text { Yes all nodes } \\
\text { need to participate }\end{array}$ & $\begin{array}{l}\text { Yes all nodes needs } \\
\text { to participate }\end{array}$ \\
\hline Distributed operations & Yes & Yes \\
\hline Proactive operations & No & No \\
\hline Loop free & Yes & Yes \\
\hline Periodic messaging & $\begin{array}{l}\text { Yes group leader sends } \\
\text { periodic hello message }\end{array}$ & $\begin{array}{l}\text { Yes source node } \\
\text { sends periodic group } \\
\text { join query message }\end{array}$ \\
\hline Routing mechanisms & Tree based routing & Mesh based routing \\
\hline
\end{tabular}

Experimental setup: VCR network has been formed with 30 PDA nodes. Each node in the network was assigned with a static IP address. The participators are a teacher and students staying in different hostels as shown in Fig. 1. The compiled final executable files have been installed on the PDAs through Microsoft ActiveSync, using Universal Serial Bus (USB) port. During the experiments, PDAs communicate with each other using the in-built Sychip Cheetah $802.11 \mathrm{~g}$ WLAN card with P2P capability. IEEE $802.11 \mathrm{~g}$ Distributed Coordination Function (DCF) Medium Access Control (MAC) sub-layer protocol is used for communications by using channel one. Initially one node is designated as the source and it transferred different Constant Bit Rate (CBR) packets per second. Tests have been carried out for different traffic, different areas and different speeds. The mobile nodes are allowed to move towards any direction. The input sample was used a multimedia file. In order to support transfer of any type of file UNIX to UNIX Encode (UUEncode) has been used to convert the file contents into ASCII characters, which can be transmitted over the network. At the destination side UNIX to UNIX Decode (UUDecode) has been done to receive the original contents of the file. The experiments have been performed for duration of $300 \mathrm{sec}$.

The performances of MAODV and ODMRP routing protocols are analyzed using group learning module of VCR. Evaluation parameters are area, network traffic and node speed. The parameter values are calculated from the log file maintained at each PDA node. The log file contains the sequence of actions performed and the necessary tables maintained by each routing protocol.

Different traffic: In VCR Application, we have compared the performance of MAODV and ODMRP for different traffic: 1, 5, 10, 20 and $50 \mathrm{KBytes} \mathrm{sec}^{-1}$. We measured the Packet Delivery Ratio (PDR) and the Latency for the two protocols. PDR is the ratio of the number of packets sent to the number of packets received and shows the reliability of the protocol. Latency is the average end-to-end packet delay (Table 2).
Table 2: Implementation parameters for the different traffic scenarios

\begin{tabular}{|c|c|}
\hline $\begin{array}{l}\text { Number of members } \\
\text { (students and teacher) }\end{array}$ & $29+1$ \\
\hline Number of teacher (sender) & 1 \\
\hline Number of receivers & 15 \\
\hline Speed & $1 \mathrm{~m} \mathrm{sec}^{-1}$ \\
\hline CBR & $1,5,10,20$ and 50 KBytes $\sec ^{-1}$ \\
\hline Area & $500 \times 500 \mathrm{~m}$ \\
\hline
\end{tabular}

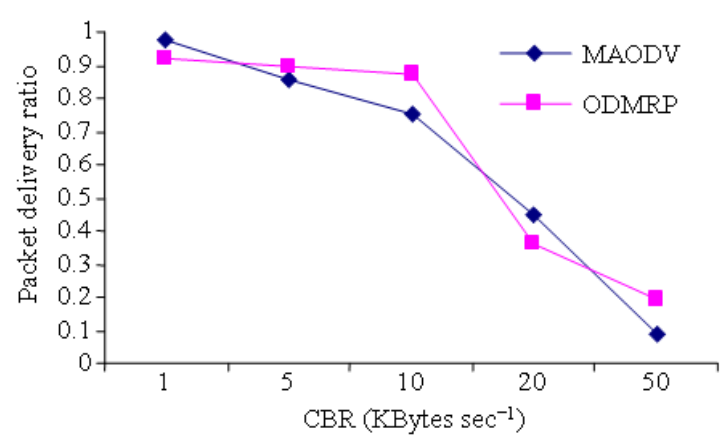

Fig. 2: Packet delivery ratio versus traffic

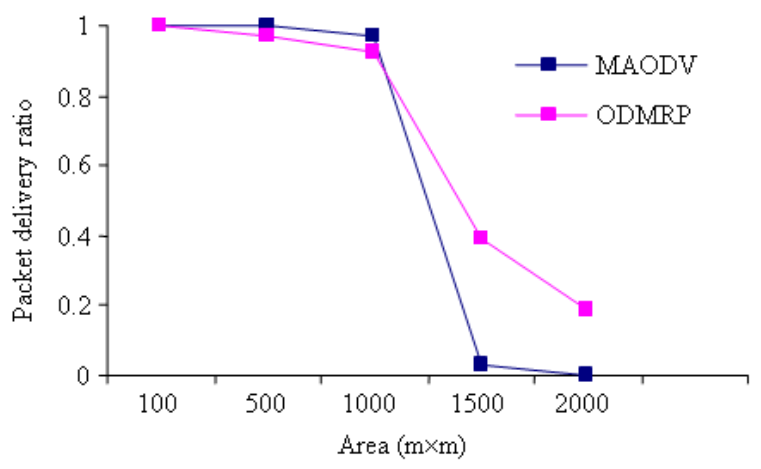

Fig. 3: Packet delivery ratio versus area

Figure 2 shows the severe PDR degradation as the traffic increases for both protocols. None outperforms the other in all cases because of higher control packet overhead leads to more collisions.

Different areas: In VCR Application, we have compared the performance of MAODV and ODMRP for different areas. The nodes may move in areas of: $100 \times 100, \quad 500 \times 500, \quad 1000 \times 1000, \quad 1500 \times 1500$ and $2000 \times 2000 \mathrm{~m}$. We have measured the PDR and the Latency for the two protocols and is shown in Table 3.

Figure 3 shows that the PDR of MAODV is better for small areas up to $1000 \times 1000 \mathrm{~m}$ because of tree link breakage and reconstruction is easy. For larger areas ODMRP performs better because of multiple routes available in the mesh network. 
Table 3: Implementation parameters for the different area scenarios

\begin{tabular}{ll}
\hline $\begin{array}{l}\text { Number of members } \\
\text { (students and teacher) }\end{array}$ & $29+1$ \\
Number of teacher (sender) & 1 \\
Number of receivers & 15 \\
Speed & $1 \mathrm{~m} \mathrm{sec}^{-1}$ \\
CBR & $1 \mathrm{KByte} \mathrm{sec}^{-1}$ \\
Area & $100 \times 100,500 \times 500,1000 \times 1000$, \\
& $1500 \times 1500$ and $2000 \times 2000 \mathrm{~m}$ \\
\hline
\end{tabular}

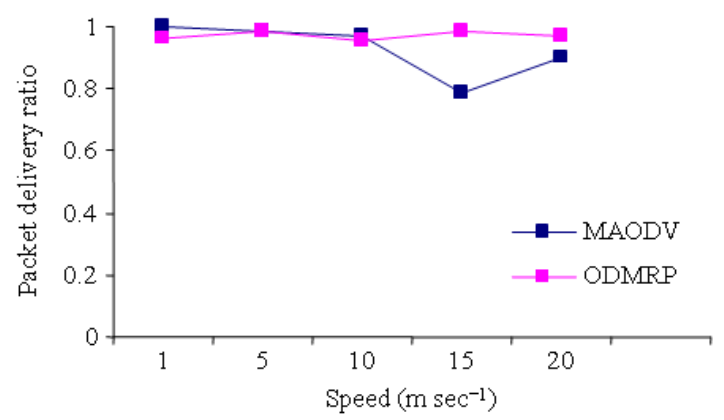

Fig. 4: Packet delivery ratio versus node speed

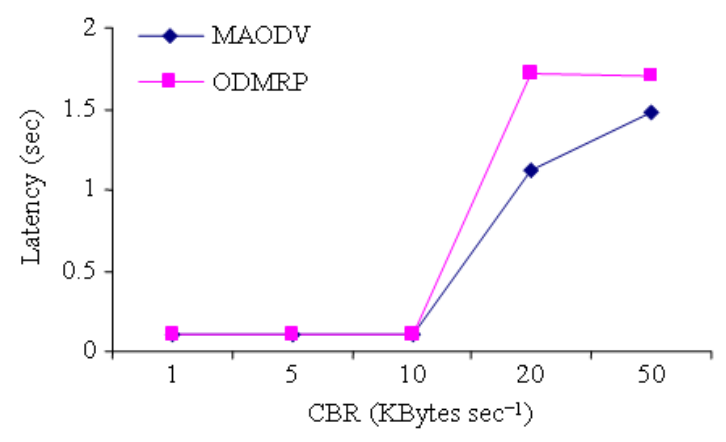

Fig. 5: Latency versus traffic

Different speeds: In VCR Application, we have compared the performance of MAODV and ODMRP for different node speeds: $1,5,10,15$ and $20 \mathrm{~m} \mathrm{sec}^{-1}$. We have measured the PDR and the Latency for the two protocols and is shown in Table 4.

Figure 4 shows that the PDR of MAODV is better for node speed up to $10 \mathrm{~m} \mathrm{sec}^{-1}$. ODMRP is not influenced by the node speed and performs better than MAODV for speed larger than $10 \mathrm{~m} \mathrm{sec}^{-1}$.

Figure 5 shows that both protocols have the same extremely small latency for traffic up to $10 \mathrm{KBytes} \mathrm{sec}^{-1}$. For heavier traffic MAODV outperforms.

Figure 6 shows that ODMRP achieves smaller latency up to areas of $1500 \times 1500 \mathrm{~m}$. In areas of 2000×2000 m MAODV achieves smaller latency.

The ODMRP's latency has been found to be the smallest for any node speed as shown in Fig. 7.
Table 4: Implementation parameters for the different speed scenarios

\begin{tabular}{ll}
\hline No. of members (students and teacher) & $29+1$ \\
Number of teacher (sender) & 1 \\
Number of receivers & 15 \\
Speed & $1,5,10,15,20 \mathrm{~m} \mathrm{sec}^{-1}$ \\
CBR & $1 \mathrm{KByte} \mathrm{sec}^{-1}$ \\
Area & $500 \times 500 \mathrm{~m}$ \\
\hline
\end{tabular}

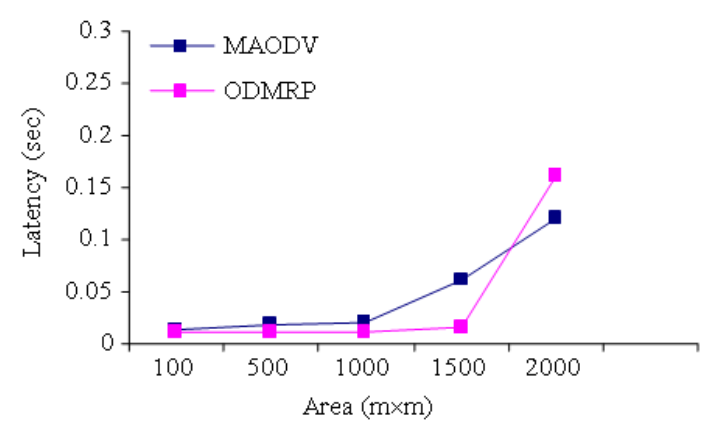

Fig. 6: Latency versus area

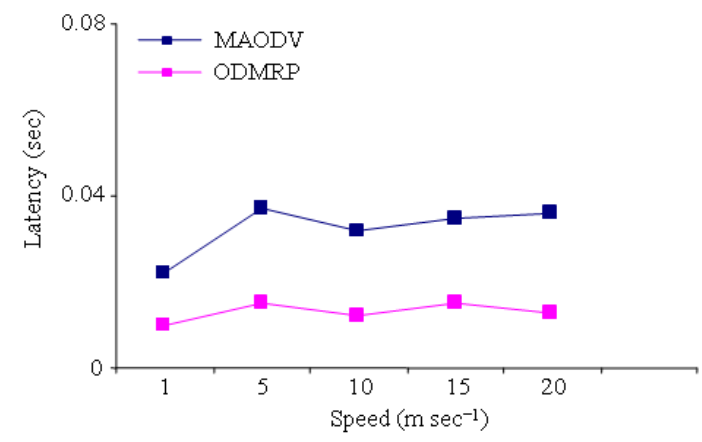

Fig. 7: Latency versus node speed

\section{CONCLUSION}

In this study, we have presented a performance comparison of MAODV and ODMRP using VCR with different implementation scenarios. For small areas, MAODV achieves better PDR while ODMRP achieves better latency. For large areas, ODMRP achieves better PDR while MAODV achieves better latency. For high traffic ODMRP is slightly better than MAODV. For different node speeds, both protocols perform well with ODMRP performing better as the speed increases. Based on this analysis, MAODV is found to provide better performance in VCR Environment.

\section{REFERENCES}

1. Garcia-Luna-Aceves, J.J. and E.L. Madruga, 1999. A multicast routing protocol for ad-hoc networks. Proceeding of the 18th Annual Joint Conference on IEEE Computer and Communications Societies, Mar. 21-25, IEEE Xplore Press, New York, USA., pp: 784-792. DOI: 10.1109/INFCOM.1999.751466 
2. Lee, S.J., W. Su and M. Gerla, 1999. On-demand multicast routing protocol for mobile ad-hoc networks.

http://www.cs.ucla.edu/NRL/wireless/PAPER/sjlee monet.ps.gz

3. Jacquet, P., P. Minet, A. Laouiti, L. Viennot, T. Clausen and C. Adjih, 2002. Multicast optimized link state routing. IETF MANET draftietf-manet-olsr-molsr-01.txt.

http://tools.ietf.org/html/draft-jacquet-olsr-molsr-00

4. Perkins, C., E. Royer and S. Das, 2003. Ad hoc On- Demand Distance Vector (AODV) routing. http://www.ietf.org/rfc/rfc3561.txt

5. Royer, E.M. and C.E. Perkins, 1999. Multicast operation of the ad-hoc on-demand distance vector routing protocol. Proceedings of the 5th Annual ACM/IEEE International Conference on Mobile Computing and Networking, Aug. 15-19, ACM Press, Seattle, Washington, USA., pp: 207-218. http://portal.acm.org/citation.cfm?id=313538
6. Sinha, P., R. Sivakumar and V. Bharghavan, 1999. MCEDAR: Multicast core extraction distributed ad-hoc routing. Proceeding of the Conference on Wireless Communications and Networking, Sept. 2124, IEEE Xplore Press, New Orleans, LA., USA., pp: 1313-1317. DOI: 10.1109/WCNC.1999.796950

7. Wu, C., Y. Tay and C. Toh, 1998. Ad hoc multicast routing protocol utilizing increasing id-numbers (AMRIS). Functional specification (Internet-Draft). http://130.203.133.121:8080/showciting;jsessionid $=6 \mathrm{D} 814 \mathrm{EA} 72 \mathrm{BC} 5 \mathrm{E} 5 \mathrm{CB} 6 \mathrm{CDA} 7077 \mathrm{D} 436 \mathrm{EF} 24$ ? $\mathrm{cid}$ $=166252$

8. Kalaavathi, B., S. Madhavi, S. Vijayaragavan and K. Duraiswamy, 2005. Virtual class room using mobile ad hoc network. Proceeding of the International Conference on e-Learning, Oct. 2005. 